\title{
EDUCAÇÃO AFROCÊNTRICA COMO \\ VIA DE LUTA ANTIRRACISTA E SOBREVIVÊNCIA NA MAAFA
}

Aza Njeri*

Resumo: Entendendo a necessidade de (re)pensar os caminhos educacionais no século XXI a partir de perspectivas plurais que tensionem a hegemonia universalizante imposta pelo ocidente, este artigo propõe refletir sobre educação por meio de uma abordagem epistemológica afrocêntrica (ASANTE, 2014) e afroperspectivada (NOGUERA, 2012). No âmbito macro, destina-se também a contribuir com a discussão étnico-racial na educação atendendo a lei 10639/o3 e seu adendo 11645/o8, promovendo caminhos para a prática educacional antirracista. Desta forma, por meio da compreensão do estado de Maafa (ANI, 1994), isto é, holocausto negro, que subjuga a população afrodiaspórica e, em específico, a afro-brasileira, trilha-se reflexões sobre prática pedagógica antirracista e apresenta o Ndezi no Parque.

Palavras chaves: Educação afrocêntrica; Afroperspectiva; Maafa, Ndezi, Literatura negra.

Resumen: En este artículo se propone reflexionar sobre la educación a partir de un abordaje epistemológico afrocéntrico (ASANTE, 2014) y afroperspectivada (NOGUERA), en el sentido de que, en el siglo XXI, a partir de perspectivas plurales que tensen la hegemonía universalizante impuesta por el occidente, 2012). En el ámbito macro, se destina también a contribuir con la discusión étnicoracial en la educación atendiendo a la ley 10639/03 y su adenda 11645/o8, promoviendo caminos para la práctica educativa antirracista. De esta forma, por medio de la comprensión del estado de Maafa (ANI, 1994), es decir, holocausto negro, que subyuga a la población afro-diaspórica y, en específico, a la afro-brasileña, se trillan reflexiones sobre práctica pedagógica antirracista y presenta la práctica pedagógica del Ndezi en el Parque.

Palabras claves: Educación afrocéntrica; Afroperspectiva; Maafa, Ndezi, Literatura negra.

\section{Introdução}

O primeiro quarto do século XXI está se mostrando tensionado. Fronteiras estão sólidas, apesar da crença na liquidez dos tempos devido à efemeridade e rapidez das conexões e desconexões que o ocidente ${ }^{1}$ nos submerge. A história mostra que em períodos de crise há o recrudescimento das ações que tangem, permeiam e/ ou perpassam as minorias; e, neste artigo, debruço-me no pensar educação e práticas pedagógicas pa-

\footnotetext{
* Dra. Aza Njeri (Viviane Moraes), pós doutoranda PPGF/UFRJ, docente UGB/NI, Negrarh/UFRJ. Email: vivimpessoal@gmail.com

${ }^{1}$ Entendendo o poder da linguística na reflexão de categorias, neste artigo a ausência de letras maiúsculas em substantivos próprios ocorre pelo não reconhecimento simbólico que este substantivo traz.
}

ra a população negra brasileira, entendida como pertencente à diáspora africana ${ }^{2}$ no brasil, além de compartilhar a experiência do Ndezi no Parque, iniciativa coletiva de pessoas negras que acreditam que a mudança vem pela via uterina-comunitária.

A constante desumanização que, entranhada ao racismo estrutural, impinge à população negra condições de holocausto e genocídio, demanda foco e atenção. Já se

\footnotetext{
${ }^{2}$ Tal nomenclatura acorda com a compreensão histórico-social do sequestro e cárcere submetido à população africana iniciado com a escravidão. Assim, os afrodescendentes são parte relevante e determinante do chamado Povo Negro, desdobrado em continentais e diaspóricos. Neste artigo, focamos especificamente na diáspora brasileira, também conhecida como afro-brasileira.
}

NJERI, Aza. Educação afrocêntrica como via de luta antirracista e sobrevivência na maafa. Revista Sul-Americana de Filosofia e Educação. Número 31: mai.-out./2019, p. 4-17. DOI: https://doi.org/10.26512/resafe.vizo.28253 
sabe que a escola é, ainda hoje, uma experiência traumática na vida das pessoas que não se adequam ao padrão ocidental de humanidade. Isto quer dizer, que desde o nosso primeiro contato com o mundo escolar, compreendemos a divisão dos que são mais ou menos humanos. Esse fato é relevante, principalmente quando sabemos que oficialmente $54,9 \%$ (IBGE, 2014) da população brasileira se autodeclara negra e parda. Isto significa que a educação, direito fundamental, introduz valores opressores e desumanizadores precocemente na forma de ser e estar de crianças afro-brasileiras.

Defendo que o padrão humano ocidental de ser se assemelha ao personagem Jordan Belfort, interpretado por Leonardo Dicaprio em seu papel no filme O lobo de Wall Street de Martin Scorsese (2014), isto é, um homem loiro, alto de olhos claros, rico, irresponsável e inconsequente, de índole duvidosa, alienado e sem empatia, morador do eixo norte do globo, em uma grande cidade, detentor de algum poder político e econômico, que, do alto de seu privilégio, decide a dinâmica do ocidente - seu mundo construído para si mesmo.

$\mathrm{O}$ que gostaria de enfatizar é que o ocidente, entendido aqui como angloeurocêntrico, composto, sobretudo, pelas grandes potências europeias como inglaterra, frança, alemanha e bélgica ${ }^{3}$, e pelos estados unidos da amerikkka4 ${ }^{4}$ é construído po-

\footnotetext{
3 Novamente a escolha pelo não uso da letra maiúscula nos substantivos próprios se dá devido à minha posição de negação simbólica conferida à esses substantivos.

4 Referência à grafia usada pelo movimento panafricano para o nome do país estados unidos da amerikkka, relacionando-o, por meio da repetição da letra $\mathrm{K}$, à ku klux klan.
}

lítico, econômico, social e culturalmente em prol deste Jordan Belfort dicapriano e quanto mais você se aproxima/distancia de Jordan, mais ou menos humano você é para a dinâmica ocidental. E a escola é um dos primeiros lugares - senão o primeiro lugar em que crianças não-brancas são diretamente expostas a essa realidade, informando-lhes constantemente qual é seu nível de humanidade, ao mesmo tempo em que deprecia sua história, sociedade, espiritualidade, ancestralidade, ciência e tecnologia.

Compreender essa questão é crucial para a obtenção da lucidez necessária para discernir as práticas pedagógicas empregadas atualmente, além de permitir uma autoavaliação por parte do docente sobre a sua atuação em prol de seu crescimento em múltiplas esferas e a consciência de si e do mundo de seus alunos. Devemos refletir que nem a concepção de humanidade, nem a de educação, deve ser universal, pois a universalidade considera apenas Jordan Belfort como modelo e tudo que difere dele ou é marginalizado ou é suprimido.

Acredito, portanto, que inserir na prática pedagógica as contribuições dos não-brancos para humanidade e expandi-la através de perspectivas não eurocêntricas no que se refere à história, cultura, língua, política, economia, tecnologia e ciência -, torna o processo ensino-aprendizagem e a socialização escolar menos traumáticos, mais plurais e emancipadores. Por conseguinte, a promoção da comunicação intercultural também ocorre de maneira mais igualitária, principalmente diante do cosmopolitismo pós-moderno, largamente propagado pelo ocidente, que faz com que, conectados, nos descrevamos como "cida- 
dãos do mundo". Indago-me, entretanto, como pensar nessa cidadania em um cenário de desumanização e genocídio? Só poderíamos, enquanto pessoas negras, ser cidadãos do mundo se, primeiramente, formos cidadãos de si. Nossa identidade cultural deve ser praticada, para que não sejamos cópias mal diagramadas da branquitude cidadã do mundo ocidental. A verdadeira cidadania do mundo deve ser integral e integrante a ele e não baseadas na sobreposição e dominação de uma cultura sobre a outra.

Isso posto, o mosaico cultural e racial presente no brasil impõe que a escola se sensibilize com os atravessamentos de ordem racista, homofóbica, machista, xenofóbica e repense suas estratégias de combate; sobretudo que ela se questione e autoavalie a sua eficácia e eficiência em relação ao seu caráter emancipador.

Dados da PNAD/IBGE (IBGE, 2014) apontam que, no ano de 2013, 79,4\% das crianças negras e pardas encontravam-se na escola nas idades de 4 e 5 anos, evidenciando que, já na primeira infância, é introduzido no conhecimento psico-cognitivo e social da criança afro-brasileira um mundo sob a perspectiva exclusivamente eurocêntrica, reprodutora de lugares comuns depreciadores e baseada em conceito de humanidade que não abarca essas crianças. Maulana Karenga (2009) aponta a questão:

Os Estudos Multiculturais se iniciaram com as lutas pelos Estudos Negros e por meio delas, com sua crítica à educação monocultural eurocentrista e sua demanda pelo fim desse padrão de educação. Nossa posição (...) é de que uma educação de qualidade é sempre, necessariamente, uma educação multicultural e que o engajamento na análise e na compreensão comparativas só pode enriquecer a aprendizagem e nossa experiência docente (KARENGA, 2009, p. 335)

Outro dado relevante a este artigo é a taxa de analfabetismo entre pessoas acima de 15 anos de idade nos anos 2013/2014 (IBGE, 2014), em que demonstra haver uma equiparação no que tange ao gênero: $8,8 \%$ entre os homens e $8,2 \%$ entre as mulheres; ao mesmo tempo em que assinala a disparidade no critério racial: 5,2\% brancos e 11,5\% negros. Na outra ponta da educação, os mesmos dados do IBGE (2014) demonstram que, enquanto $23,3 \%$ das pessoas brancas possuem ensino superior, apenas $8,4 \%$ da população negra e parda brasileira possuem a mesma escolaridade.

\section{Maafa: holocausto negro e a educação antirracista}

A escravidão transatlântica, cujos pilares são o racismo e o mercantilismo (MOORE, 2012), é um fenômeno próprio, incomparável a qualquer outro exemplo de sistemas de escravidão, além de ter consequências únicas que atuam e determinam os caminhos de todo um contingente populacional da raça negra. Assim, a travessia do atlântico plantou suas raízes no profundo inconsciente coletivo negro, ao mesmo tempo em que iniciou o processo de holocausto africano, que atravessa e determina a relação desses corpos com o ocidente, desumanizando-os. 
Os fenômenos de sequestro, cárcere, escravidão, colonização, objetificação, guetificação e genocídio que a população negra, independente da territorialidade, sofre diretamente desde 1500, chama-se Maafa (ANI, 1994).

Maafa é, desta maneira, o processo de sequestro e cárcere físico e mental da população negra africana, além do surgimento forçado da afrodiáspora. Este termo foi cunhado por Marimba Ani (1994), e corresponde, em Swahili, à "grande tragédia", à ocorrência terrível, ao infortúnio de morte, que identifica os 500 anos de sofrimento de pessoas de herança africana através da escravidão, imperialismo, colonialismo, apartheid, estupro, opressão, invasões e exploração.

É o genocídio histórico e contemporâneo global contra a saúde física e mental dos povos africanos, afetando-os em todas as áreas de suas vidas: espiritualidade, herança, tradição, cultura, agência, autodeterminação, casamento, identidade, ritos de passagem, economia, política, educação, arte, moral e ética. Desta forma, os africanos sofrem o trauma histórico da sua desumanização e reproduzem as violências, contribuindo - e muitas das vezes facilitando o trabalho - para o genocídio.

Ao focarmos nosso olhar na prática pedagógica, devemos considerar o estado de maafa em que se encontra a população negra brasileira na contemporaneidade e o seu reflexo na educação. Problemas como a violência generalizada, instabilidade familiar, racismo estrutural, nutricídio, racismo religioso, machismo, homofobia, pobreza/ miserabilidade e ausência de perspectivas são barris de pólvora que costumam estar com pavios acesos no ambiente escolar. Assim, entender que as possibilidades de vida dos estudantes negros são tangenciadas pela (falta de) perspectiva em manter-se vivo.

A metáfora do genocídio, a qual sempre recorro, entende-o como um monstro com diversos tentáculos. Esse monstro mira o corpo negro a fim de matá-lo física, psicológica, epistemológica e espiritualmente. Ciente da complexidade e a heterogeneidade que é o Povo Negro, cada tentáculo é responsável por uma área do genocídio, assim, temos desde nutricídio, epistemicídio, racismo religioso, encarceramento em massa, ultraviolências homofóbicas e internação compulsória em hospitais psiquiátricos, até a efetiva morte física de toda a população negra, sem exceção ou recortes. Ou seja, não importa a especificidade deste corpo negro, o monstro do genocídio é sofisticado o suficiente para adequar-se a ela e utilizála como via de morte.

Assim sendo, uma educação antirracista e emancipadora deve preparar o sujeito negro para ser lúcido e crítico diante desta realidade, permitindo a sua autodeterminação e autoproteção enquanto ser humano, pois ele é o alvo principal deste monstro e não pode ser alienado em relação a este fato. E, as crianças não-negras que acessarão essa educação, compreenderão que o mundo não gira em torno de si, seus valores e culturas, fazendo com que cresçam com mais empatia, menos racistas e conscientes de seu papel no mundo.

\section{Abordagem afrocêntrica como suleado- ra da prática pedagógica}


'Pensar a prática pedagógica a partir de uma perspectiva suleadora, que quer partir do sul, "com o sul e ir para o sul" (SANTOS, 2009, p. o9) requer, inicialmente, que se questione a epistemologia dominante definidora da educação brasileira. É um fato que a estrutura da educação nacional, seus objetivos e suas práticas são reprodutores da universalidade científica homogeneizadora que o ocidente impõe a todos aqueles que o tocam:

(...) a epistemologia dominante é, de facto, uma epistemologia contextual que assenta numa dupla diferença: a diferença cultural do mundo moderno cristão ocidental e a diferença política do colonialismo e do capitalismo. (...) Esta dupla intervenção foi de tal maneira profunda que descredibilizou e, sempre que necessário, suprimiu todas as práticas sociais de conhecimento que contrariassem os interesses que ela servia. Nisso consistiu o epistemicídio, ou seja, a supressão dos conhecimentos locais perpetrada por um conhecimento alienígena. De facto, sob o pretexto da 'missão colonizadora', o projeto da colonização procurou homogeneizar $o$ mundo, obliterando as diferenças culturais. Com isso, desperdiçou-se muita experiência social e reduziuse a diversidade epistemológica, cultural e política do mundo. (SANTOS, 2009, p.10).

Percebendo a necessidade de, no âmbito epistemológico, contribuir com a prática pedagógica na luta antirracista, atento-me à abordagem do paradigma da afrocentricidade, elucidado por Asante (2014), em que pressupõe a localização e a agência para uma mudança de paradigma:
"Assim, a afrocentricidade é uma perspectiva filosófica associada com a descoberta, localização e realização da agência africana dentro do contexto de história e cultura" (ASANTE, 2014, 04). Agência significa que toda a ação que permeia a população africana diaspórica e continental - nos âmbitos político, econômico, bélico, social, cultural, artístico, educacional, espiritual, psicológico, epistemológico -, deve ser fundamentada em experiências e elaborações oriundas dessa mesma população.

Desta forma, acessaríamos, ainda nas fases da aprendizagem infanto-juvenil, informações sobre grandiosidade do Império do Mali, tal qual aprendemos sobre o império romano; leríamos nas creches as obras infantis de Lívia Nathália, Ondjaki, Bell Hooks assim como lemos as de Ruth Rocha e Ana Maria Machado; aprenderíamos geometria a partir da etnomatemática; além de cantarmos no recreio canções de jongo junto da "ciranda-cirandinha". Acredito que os ganhos de conhecimento de mundo e a aprendizagem aguçam-se a partir da multiplicidade de abordagens e faz com que tanto crianças negras e pardas, quanto as brancas tornem-se respeitadoras, éticas, empoderadas e tolerantes.

Sinto coerente resgatar o tempo em que estudei o Egito na quinta série do ensino fundamental de uma escola filantrópica no bairro da Tijuca/RJ, na década de 1990. Nesta escola a maioria dos alunos eram negros oriundos de diversas partes da cidade, e sobretudo das diferentes comunidades na Tijuca e arredores; nossos professores eram todos brancos - não consigo lembrar de nenhum professor negro em todo o meu ensino fundamental. Assim, ao aprender sobre 
essa região africana, berço da civilização, me foram negadas informações de caráter emancipador que, para além de não permitir que eu conseguisse localizar o território no mapa - imaginar que ficava na África, impossível! -, fez com que eu acreditasse naquela "verdade histórica" e reproduzisse informações depreciadoras e incorretas sobre a história de um povo negro-africano detentor de conhecimento e tecnologia ultrassofisticados.

Não me foram apontadas informações pertinentes para a localização e perspectiva daquele espaço e daquela civilização. Fatos como a alta concentração de melanina na população egípcia, cujo nome africano é Kemet - e eu poderia escrever um ensaio sobre a dominação simbólicolinguística imposta pela europa na África; ou a presença de gregos estudando nas escolas egípcias/keméticas compreendidas como templos de sapiência e evolução, ajudariam a nossa experiência de aprendizado nesse tema de forma instigante e movimentadora da consciência crítica.

Em relação à Sócrates e Aristóteles e
a maioria dos filósofos pré-
socráticos, a história parece ser
omissa sobre a questão da sua via-
gem para o Egito, (...) com o propó-
sito de sua educação. É o suficiente
dizer que, neste caso, as exceções
provaram a regra, que todos os es-
tudantes, que tinham os meios, fo-
ram para o Egito para completar sua
educação. (JAMES, 1954, p. 53)

Ainda dentro dessa perspectiva, entende-se que também não se estuda a história da América e, sim, a história dos europeus no continente americano. Nas aulas de história somos informados sobre a chegada de Colombo em 1492 ao continente, sem fornecerem perspectivas plurais de tal fato. Isto quer dizer que, dentro da abordagem afrocêntrica, ao colocarmos a localização e a agência negra enquanto perspectiva, perceberemos que Colombo foi um genocida da população ameríndia, assim como os demais europeus invasores do novo mundo, como nos aponta a intelectual afrocolombiana Rosa Plummelle-Uribe (2018):

Os historiadores do século XX, estudando a conquista da América, chegaram mais ou menos a acordo na estimativa do número de habitantes do continente americano antes da invasão. Afirmou-se então que, antes de 1500 , por volta de 80 milhões de pessoas habitavam o continente americano. estes números foram comparados aos obtidos cinquenta anos mais tarde de recenseamentos espanhóis.

Concluiu-se, então, que, por volta de 1550 , de 80 milhões de indígenas não restava mais que 10 milhões. $\mathrm{Ou}$ seja, em termos relativos, uma destruição da ordem de $90 \%$ da população. (...) E mais importante, saber que, nos últimos anos, historiadores sul-americanos chegaram à conclusão que, na realidade, nas vésperas da conquista, havia na América mais de 100 milhões de habitantes. (...) estaríamos perante uma diminuição de 90 milhões de seres humanos. (PLUMMELLE-URIBE, 2018, p.62).

A questão da escravidão também deve ser refletida: a escola reduz a história do negro africano, e as contribuições de sua diáspora à amérikkka branca, à escravidão, dança, folclore e esportes. Esquece de ensi- 
nar que a escravidão começa com os árabesmuçulmanos (MOORE, 2012), que implantaram o sistema no continente africano para suprir as demandas de mão de obra para o seu império oriental e para as regiões europeias dominadas por eles neste período histórico. Os europeus, no caso, sofisticaram o método elevando-o à enésima potência.

O sistema escravista desenvolvido durante sete séculos pelos árabes muçulmanos elegeu o continente africano, partindo da África do Norte, como o centro fornecedor da mercadoria que se buscava - negros escravizados - para ser submetidos a trabalhos domésticos, serviço de arma, trabalho agrícola e ser utilizada como moeda internacional. Essas demandas da sociedade árabemuçulmana desestruturaram e destruíram as bases sociopolíticas de muitas sociedades africanas, pois foram política, econômica e militarmente obrigadas a ceder às pressões de um mercado escravocrata externo. Esse desenvolvimento avassalador do comércio de escravos chegou até a Europa - que se tornou herdeira do sistema escravista, sofisticando a cultura da escravidão -, assim como fizeram os árabes quando o herdaram dos gregos e bizantinos. (MOORE, 2012, p.78)

Renato Noguera (2012) desdobra o conceito de afrocentricidade de Asante, trazendo a ideia de afroperspectiva, termo que em sentido simples, aborda o "conjunto de pontos de vista, estratégias, sistemas e modos de pensar e viver de matrizes africanas" (NOGUERA, 2012, p.147). Assim, ao pensarmos a educação da diáspora afrobrasileira, devemos em primeiro lugar localizá-la e aplicar sua agência, para logo em seguida, afroperspectivar a partir da territo- rialidade brasileira e a história desta diáspora.

Uma pedagogia afrocêntrica e afroperspectivada não tem caráter excludente, pois busca na natureza xenofílica negraafricana (DIOP, 2014) a base e paradigma para o relacionamento social. Sendo assim, ao empregá-la no processo educacional, deve-se também fazer o exercício de deslocamento para o eixo civilizatório africano e afroperspectivá-lo a partir da experiência da territorialidade afrodiaspórica, em específico, afro-brasileira.

Em nosso caso, portanto, acredito que o conceito de quilombismo de Abdias Nascimento (1980), o estudo dos quilombos feito por Beatriz Nascimento (2018) e o conceito de amefricanidade de Lélia Gonzalez (2018) apontam o caminho para a abordagem afrocêntrica a partir da nossa territorialidade. Benedicto (2016) afroperspectiva a educação afrocêntrica definindo-a como Educação Quilombista, isto é,

um processo de transmissão dos valores, crenças, costumes e conhecimentos para que os afro-brasileiros possam viver de maneira adequada nesta sociedade garantindo, assim, a continuidade do seu povo e de sua cultura. Esta educação deve ser inspirada na experiência dos quilombos, visto que estas sociedades permitiram aos africanos existirem nesta terra sem renunciarem a sua africanidade, além de serem abertas aos indígenas e brancos excluídos do sistema colonial. Assim como os quilombos se constituíram como espaços de construção da identidade afro-brasileira e de resistência à aculturação europeia a educação quilombista, hoje, deve ser concebida como um processo de formação 
amefricano do Brasil e de resistência ao historicamente constituído modelo eugênico e eurocêntrico de educação com vistas à construção da sociedade democrática intercultural quilombista. (BENEDICTO, 2016, p. 255)

A educação afrocêntrica apresenta um tripé estruturante: conhecimento acadêmico, conhecimento de mundo, conhecimento de seu povo e história. Ela também deve conduzir, encorajar e dirigir os estudantes para as tecnologias do futuro, de forma a garantir a sua sobrevivência na contemporaneidade.

Estudantes negros devem ter pro-
funda compreensão das realidades
política, racial, econômica, científi-
ca e tecnológica que confrontam a
sobrevivência de pessoas africanas
local, nacional e internacionalmen-
te. Eles têm que estar fundamenta-
dos em uma visão de mundo que
promova a comunicação inter-
cultural, o entendimento e o com-
partilhamento; eles ainda têm que
ser auto-protetivos o suficiente para
perceber que o mundo não é justo e
que os próprios interesses muitas
vezes entram em conflito com os in-
teresses dos outros, especialmente
quando a raça está envolvida.
(MADHUBUTI,199o, p.o3)

Diante disso, compreendo que a pedagogia afrocentrada sobre a afroperspectiva brasileira oferece suporte à linha de resistência na luta antirracista e anti genocida, além de produzir uma educação que "contribua para alcançar orgulho, equidade, poder, riqueza e continuidade cultural para os africanos na América e noutros países.” (MADHUBUTI, 1990, p. 11).

\section{Ensino de literaturas africanas e afro- brasileiras}

A literatura é uma das formadoras do imaginário social sendo, portanto, necessário pensar no papel que desempenha também como formadora de identidade, cultura e sua via refletora da sociedade, seu bem cultural:

\begin{abstract}
No mundo atual, no contexto global, a literatura (...) é vista como um produto cultural, o que ela sempre foi, como texto que se produz em contextos sociais e culturais definidos. Cada vez mais o escritor toma consciência de que a literatura tem, sim, uma função social e, ainda que não tenha o poder de mudar o mundo, ela [a literatura] tem sido um instrumento poderoso de instrução e educação. (FONSECA, 2015, p 56)
\end{abstract}

Sendo assim, devemos questionar a forma como a literatura é abordada não apenas em sala de aula, mas, sobretudo, na formação de professores. Ressalta-se que, no que tange à formação sobre África e negritude, apesar dos inúmeros esforços de pesquisadores e docentes, ainda é muito aquém do desejado e exigido pela lei 10639/03 e seu adendo 11645/o8, não sendo uma surpresa o cenário depreciativo e excludente imposto a tais temas.

No que se refere às Literaturas Africanas, ainda há, por parte do mercado editorial e da academia, uma tendência a privilegiar escritores africanos de ascendência europeia ou miscigenados e, sobretudo, que apresentem um discurso consonante com a 
perspectiva eurocêntrica de mundo. Não desmerecendo suas escritas, muito menos entrando em processo comparativo, mas compreendendo que para além da fruição literária que busca o grau zero da escritura (BARTHES, 2014), a literatura é um agente político que atua na construção simbólica do mundo, desta forma, é imprescindível tensionar a questão e buscar movimento sobre ela.

Maria Nazareth Soares Fonseca (2015) aborda a discussão:

Listas de autores e de obras considerados indispensáveis à formação do leitor literário continuam a ser produzidas com o intuito de se propor um elenco de obras vistas como excepcionais, ainda que, na maioria das vezes, sempre se tome a Europa e os Estados Unidos como se representassem o mundo inteiro. Mesmo em relação a seleções de títulos de cunho nacional, com frequência, na maioria das vezes, elas referendam as escolhas de críticos, escritores e professores. Todos sabemos que as listas de obras literárias tidas como imprescindíveis à formação do leitor, mesmo obedecendo a diferentes critérios de seleção, embasam-se na defesa de valores tidos como fundamentais à sociedade. $\mathrm{O}$ espectro da formação do leitor confunde-se, com frequência, com a formação do cidadão ideal. (FONSECA, 2015, p. 53-54)

Na literatura brasileira, o mesmo acontece, embora por trilhos diferentes, já que facilmente identificamos a ausência de Carolina Maria de Jesus, o apagamento de Maria Firmina dos Reis e Luís Gama enquanto expoentes de um discurso vivo e racializado na literatura brasileira, e o câ- none nacional como elemento excludente de literaturas não hegemônicas:

Observando-se o contexto de enunciação de muitos desses escritores e a biografia de cada um deles, há que sempre e em quaisquer circunstâncias realçar o lugar ímpar que Machado de Assis, Mário de Andrade, Cruz e Souza e Lima Barreto ocupam, por sua maestria literária e sua importância cultural, no cânone da Literatura Brasileira, e a atenção devida a outros tantos escritores ainda pouco expostos ao olhar do público e da crítica, como, por exemplo, Luiz Gama e Solano Trindade (...) (MARTINS, 2010, p. 110)

Sendo a literatura portadora do papel social emancipador, cabe entendê-la e estudá-la sob a ótica afroperspectivista e afrocêntrica: localiza-se a obra - autor, período, léxico, ideias/mensagens - e identifica-se a agência que determina a mensagem da obra, verificando, portanto, se a perspectiva contida é eurocêntrica ou parte de outras epistemologias. Assim, a leitura de textos considerados canônicos pelo ocidente é apreendida na abordagem afrocêntrica a partir de seu entendimento localizado em que não apenas a escrita literária é analisada, mas também o contexto histórico-social e, sobretudo, a legitimação do discurso que a obra traz consigo. Como evidencia Alfredo Bosi (1992) ao referir-se a O guarani de José de Alencar, considerada obra fundadora da literatura brasileira:

O índio de Alencar entra em íntima comunhão com o colonizador. Peri é, literal e voluntariamente, escravo de Ceci, a quem venera como sua Iara, "senhora', e vassalo fidelíssimo de dom Antonio. No desfecho do 
romance, em face da catástrofe iminente, o fidalgo batiza o indígena, dando-lhe o seu próprio nome, condição que julga necessária para conceder a um selvagem a honra de salvar a filha da morte certa a que os aimorés tinham condenado os moradores do solar. (BOSI, 1992, p. 177)

Reflete-se, portanto, acerca do objetivo de uma obra fundadora da literatura brasileira, enaltecida, apresentar o indígena nativo como um refletor do status quo lusoeuropeu, em um momento em que se queria legitimar a identidade nacional por meio do pensamento e ação de uma elite lusobrasileira.

A literatura, arma ferocíssima da realidade aguda, anda de mãos dadas com a ontologia e a epistemologia, sendo, portanto, imprescindível um olhar que não se atenha apenas no estético-literário, mas que também consiga ver na tessitura textual caminhos de movimento e emancipação.

\section{Ndezi no Parque: uma prática afrocên- trico-pedagógica}

Em julho de 2018, em parceria com o Coletivo Negro Denegrir/UERJ e como parte da pesquisa de pós-doutoramento que realizo no Programa de Pós-Graduação de Filosofia/UFRJ, ministrei na sala Abdias Nascimento, na UERJ, a "Ndezi: I formação afrocêntrico-pedagógica" para educadores negros. Foram dois encontros de cinco horas de duração: no primeiro ministrei a palestra "África \& diáspora: história, cultura e sociedade" em que tracei um panorama da história e cultura africanas a partir da perspectiva afrocêntrica, evidenciando o apa- gamento histórico e empoderando os educadores sobre África e sua diáspora. Como embasamento teórico busquei Cheikh Anta Diop, Marimba Ani, Carlos Moore, Molefi Kete Asante, Ivan Sertima, Wade Nobles, Ama Mazama, Frantz Fanon, Abdias Nascimento, Beatriz Nascimento, Lélia Gonzalez, Joel Rufino, Nei Lopes entre outros.

Estavam presentes no encontro vinte e quatro educadores negros, de diferentes áreas, que no segundo encontro trouxeram as suas práticas de luta antirracista para discussão conjunta, de forma a nos ajudar a sulear nossas didáticas e na produção de material. Ao fim desta experiência, percebi o quanto potencializados e confiantes nas trocas nós estávamos, sendo, então, um momento oportuno para um novo passo: em conjunto com um coletivo de negros Aya Pan-Áfrika - de diferentes áreas, iniciamos as atividades mensais, sempre aos domingos, no Parque de Madureira/RJ com crianças negras de 2 a 13 anos e suas famílias, chamada Ndezi no Parque.

Enquanto africanos brasileiros que somos, compreendemos o nome como uma parte integrante do nosso ser (Asante, 2009), desta forma, a nomeação da atividade se baseou em Fu Ki Au e LukondoWamba na obra Kindezi: the Kôngo art of babysitting (200o), em que nos são apresentados os conceitos africanos de Kindezi e Ndezi:

Kindezi, a arte de cuidar de crianças, é uma arte antiga entre os africanos, em geral, e os Bantu, em particular. É basicamente a arte de tocar, cuidar e proteger a vida da criança e do ambiente, Kinzungidila, em que o desenvolvimento multi- 
dimensional da criança ocorre. A palavra "Kindezi", um termo da língua "Kikôngo", deriva do verbo raíz Ieia, que significa desfrutar de tomar e dar cuidados especiais.

Cuidar de crianças - Ieia, ou seja, dar cuidados especiais - é, antes de tudo, uma forma de transferir padrões sociais para os membros mais jovens da comunidade. E, em segundo lugar, é a orientação da criança para a vida que compreende orientações muito bem determinadas de acordo com as normas e valores comunitários. (ANI, 2018, s/p)

Ndezi seria, assim, o cuidador da criança, aquele responsável por "ajudar esse 'sol vivo' a brilhar e crescer em seu estágio inicial" (ANI, 2018):

Ndezi, aquele que pratica a arte da Kindezi, o cuidador de crianças, não é para ser confundido com uma doula, uma ama. Em primeiro lugar, Ndezi, lida não apenas com bebês, mas com crianças e com o cuidado que deve ser dado a elas (ANI, 2018, $\mathrm{s} / \mathrm{p})$.

A partir deste processo de suleamento de nossas práticas, escolhemos o Parque de Madureira/RJ, como espaço condizente com a proposta africana de educação, cuja hierarquia ocorre de modo circular, permitindo que a dinâmica ensino-aprendizagem seja calcada, não na passividade hierárquica de transmissão vertical de conhecimento, mas nas experiências circulares e ativas que aquele ambiente fomenta. Assim, essa iniciativa soou como a possibilidade de vida na maafa brasileira, pois, uma vez por mês, nós, negros e nossas famílias convivemos sob uma perspectiva que centra-se em nos- so eixo civilizacional africano e afrodiaspórico, de forma a fazer brilhar os nossos sóis (KI.AU; LUKONDO-WAMBA, 200o), educando e potencializando nossos filhos e a nós mesmos sobre a herança que o Povo Negro tem. Portanto, no sentido mais profundo, Ndezi no Parque representa, para nós, um fôlego curativo e, sobretudo, a possibilidade de garantir lucidez, consciência e sobrevivência dos nossos.

Foram até o presente momento cinco encontros (setembro, novembro e dezembro/2018; janeiro e fevereiro/2019), cada um com temática suleadora e abordagem embasada no eixo civilizatório africano. Isto quer dizer que fazemos uma libação aos ancestrais e um café da manhã coletivo, buscando praticar o senso de comunidade chamado de Njia: "A prática do Njia (...) constitui o início da reconstrução. As pessoas que chegam ao Njia normalmente passaram por uma fase de definição. O Njia baseia a reconstrução. (...) Os encontros do Njia acontecem aos domingos para renovar forças." (Asante, 2014, p.38).

As atividades do Ndezi no Parque operam sobre a perspectiva afrocêntrica Kawaida, apresentada por Maulana Karenga (2009)

Realizarei essa iniciativa de uma perspectiva kawaida, isto é, uma perspectiva cultural crítica que privilegia a tradição, requer a razão e insiste na prática ao apreender o conhecimento e provar seu valor final. Kawaida é uma filosofia da mudança cultural e social que tem como um de seus princípios centrais a premissa que a cultura é o terreno de autocompreensão e de autorrea- 
lização e de que ela requer o diálogo. (KARENGA, 2009, p. 240)

A partir do Kawaida e da celebração de Kwanzaa, ambos cunhados por Maulana Karenga na década de 1960, nos debruçamos sobre os sete princípios de Nguzo Saba (KARENGA, 2009) para sulear as atividades. São eles: Umoja (unidade), Kujichagulia (autodeterminação), Ujima (trabalho coletivo e responsabilidade), Ujamaa (economia cooperativa), Nia (propósito), Kuumba (criatividade) e Imani (fé). Deste modo, além de nos pautarmos nesses princípios que buscam o Renascimento Negro (ASANTE, 2009), elencamos a Ujamaa como o conceito eixo das atividades de 2018 e Ujima como o de 2019 .

Em setembro, após algumas atividades organizativas do encontro, nós iniciamos o Ndezi no Parque de forma prática. Todos os participantes são convidados via whatsapp ou pessoalmente, a partir de algum contato próximo que nos permita perceber o alinhamento de perspectiva racial, já que o critério determinante para o convite é o fato de todos os participantes terem de ser negros.

Assim, neste primeiro Ndezi focamos no corpo a partir de atividades conduzidas pelo professor de capoeira Ilram Baobá, que trouxe reflexões sobre a nossa consciência holística e o movimento de nosso corpo sobre a ótica circular de esu. Fechamos atividade ao som de músicas negras tocadas pelo violinista Pedro Moreira.

Cientes do poder dos símbolos, presenteamos crianças e famílias com objetos que remetam a prática pedagógica do dia, assim entregamos, neste dia, aos participan- tes livros de colorir com motivos afrocêntricos, feitos por nós mesmos em uma impressora caseira.

O Ndezi de novembro - não fizemos em outubro por motivo de chuva na data marcada -, teve como tema Ngola Djanga, nome africano para Quilombo dos Palmares, república africana no brasil que durou quase 100 anos resistindo e determinando a trajetória de luta negra nesta maafa (NASCIMENTO, 2018). Esta atividade foi simbólica no que tange o resgate e a ressignificação dos símbolos. As crianças fizeram uma maquete do Quilombo dos Palmares a partir da perspectiva afrocêntrica e depois apresentaram para todos; elas também brincaram de bola e pique-pega e, ao fim, foram tomar banho no chuveirão que tem no parque.

Ao mesmo tempo, os adultos jogaram um quiz afrocêntrico de perguntas e respostas elaborados por mim e pelos membros desse coletivo, de forma que testamos nossos conhecimentos sobre cultura, povo, história Negra. Esse jogo foi um sucesso e sua vantagem é que podemos estar sempre criando novas perguntas para complementá-lo. O mimo deste mês foi uma imagem de Zumbi e Dandara (retirada da internet) para ser exposta em casa em um quadro ou porta-retrato de forma a reverenciar esses dois ancestrais e a resistência que eles simbolizam.

Como não podia deixar de ser, o Ndezi no Parque de dezembro foi sobre Kwanzaa e, para mim foi um dos mais bonitos e harmoniosos. As crianças fizeram uma apresentação em cartaz sobre a celebração afrodiaspórica do Kwanzaa e os sete princípios do Nguzo Saba. Com os adultos, o pro- 
fessor de química Tony Ruan conduziu uma conversa sobre alimentação saudável com base holística africana. Foi um momento de muita troca para pensarmos a nossa alimentação e a de nossos filhos. O presente do dia foi uma impressão feita por nós mesmos de um livreto sobre Kwanzaa.

Janeiro de 2019 fizemos o Ndezi de Férias. O professor Ilram Baobá novamente fez uma atividade com o corpo, mas desta vez foi exclusivo para as crianças, que também trouxeram roupas de banho e aproveitaram o dia no chuveirão do parque. Nós fizemos um grande piquenique que durou o dia inteiro. Celebramos o Njia e os ancestrais, mas sobretudo, agradecemos o fato de sobrevivermos a essa maafa e podermos estar juntos em comunhão.

Compreendendo a violência sistêmica da qual somos alvo, a atividade com os adultos focou na feitura cordões clânicos, isto é, pulseiras masculinas e tornozeleiras femininas representativas de seu clã. En- quanto fazíamos, conversamos sobre nossas experiências em afrocentrar a educação dos erês e Iya Olujimi puxou uma discussão sobre autocuidado a partir das ervas.

Em fevereiro começamos a sulear as atividades a partir do conceito de Ujima e trabalhamos com o resgate da memória, por meio de fotos e desenhos que as crianças levaram/fizeram de seus ancestrais; elas também brincaram de jogos como "cabracega" e "corre cutia", enquanto os adultos conversavam sobre a ancestralidade e as vivências diárias.

A experiência do Ndezi tem sido extremamente enriquecedora, mas acredito que o maior ganho é a possibilidade de, mensalmente, estar entre pessoas pretas pensando e praticando a nossa emancipação a partir do entendimento do nós por nós. Está aí uma prática que pode ser adaptada e copiada pelos diversos quilombos mundo afora.

\section{Referências}

ANI, Marimba. "Introdução". In: Kindezi. A arte do cuidado da criança e do corpo social. FU KI.AU, K. Kia Bunseki; LUKONDO-WAMBA, A. M. Kindezi: Kôngo art of babysitting. Disponível em: http://terreirodegriots.blogspot.com/2018/o8/kindezi-ar

te-do-cuidado-da-crianca-e-do.html.

. Yurugu - uma crítica africano-centrada do pensamento e comportamento cultural europeu. Trenton, Africa Word Press, 1994. Disponível em: https://estahorareall.wordpress.com/2015/o8/o7/dr-marimba-ani-yurugu-uma-critica-africanocentrada-do-pensamento-e-comportamento-cultural-europeu/

ASANTE, Molefi K. Afrocentricidade. Philadelphia: Afrocentricity International, 2014. BARTHES, Roland. O grau zero da escrita. 2.ed. São Paulo: Martins Fontes, 2014.

BENEDICTO, Ricardo Matheus. Afrocentricidade, educação e poder: uma crítica afrocêntrica ao eurocentrismo no pensamento educacional brasileiro. Tese (Doutorado em Educação) - Faculdade de Educação. Universidade de São Paulo. 2016.

BOSI, Alfredo. Dialética da colonização. São Paulo: Cia das Letras, 1992. 
BRASIL. IBGE. Uma análise das condições de vida da população brasileira, 2014. Disponível em:https://ww2.ibge.gov.br/home/estatistica/populacao/condicaodevida/indi cadoresminimos/sinteseindicsociais2014/default_tab_xls.shtm.

DIOP, Cheikh Anta. A unidade cultural da África negra. Luanda: Edições Mulembra, 2014.

FONSECA, Maria Nazareth S. Literaturas africanas de língua portuguesa: mobilidades e trânsitos diaspóricos. Belo Horizonte: Nandyala, 2015.

FU KI.AU, K. Kia Bunseki; LUKONDO-WAMBA, A. M. Kindezi: Kôngo art of babysitting. Baltimore: Black Classic Press, 2000.

GONZALEZ, Lélia. Primavera para as rosas negras. São Paulo: Diáspora Africana, 2018.

JAMES, George. Stolen Legacy. Arkansas: Pine Bluff, 1954.

KARENGA, Maulana. A função e o futuro dos estudos africana: reflexões críticas sobre sua missão, seu significado e sua metodologia. In: Nascimento, Elisa L. (Org.). Afrocentricidade: uma abordagem epistemológica inovadora. São Paulo: Selo Negro, 2009. p. 333-359.

MADHUBUTI, Haki; MADHUBUTI, Safisha. Educação afrocentrada: Seu valor, importância e necessidade no desenvolvimento de crianças negras. Trad. Roberta Maria Federico (2018). In: Journal of Education. Boston. v. 172. n.2. 1990.

MARTINS, Leda. "Lavrar a palavra: uma breve reflexão sobre a literatura afro-brasileira”. In: Pereira, Edimilson de Almeida. (Org.). Um tigre na floresta de signos: estudos sobre poesia e demandas sociais no Brasil. Belo Horizonte, Mazza Edições, 2010.

MOORE, Carlos. Racismo e sociedade: novas bases epistemológicas para entender o racismo. Belo Horizonte: Nandyala, 2012.

NASCIMENTO, Abdias. O quilombismo. Petrópolis: Vozes, 1990.

NASCIMENTO, Beatriz. Beatriz Nascimento - Intelectual e quilombola. São Paulo: Diáspora Africana, 2018.

NOGUERA, Renato. "Afrocentricidade e educação: os princípios gerais para um currículo afrocentrado”. In: Revista África e africanidades. v. 3. n.11. nov 2010. Disponível em: http://www.africaeafricanidades.com.br/documentos/o1112010_02.pdf

. "Ubuntu como modo de existir: elementos gerais para uma ética afroperspectivista". In:

Revista da ABPN. v.3. n.6. p. 147-150, nov./fev., 2011-2012.

PLUMMELLE-URIBE, Rosa Amelia. “Da barbárie colonial à política nazista de extermínio”. In: União dos coletivos pan-africanistas (Org.). Coleção pensamento preto: epistemologias do renascimento africano. São Paulo: Diáspora Africana, 2018.

SANTOS, Boaventura S., MENESES, Maria Paula. Epistemologias do sul. Coimbra: Edições Almedina, 2009.

SERTIMA, Ivan Van. They came before Columbus. The african presence in Ancient America. Nova York: Random House Trade Paperbacks, 1976.

\section{Audiovisual}

O lobo de Wall Street. Direção: Martin Scorcese, Produção: Martin Scorsese. EUA: Universal Pictures, 2014 .

Recebido em: 05/06/2019 Aprovado em: 31/10/2019 